\title{
Kütahya (Çavdarhisar) Yöresinde Yetiştirilen Tıbbi Adaçayı (Salvia officinalis L.) Türünün Çiçeklerindeki Uçucu Yağ Bileşenlerinin Değerlendirilmesi
}

\author{
Hasan Basri Karayel ${ }^{1 *}$ \\ ${ }^{1}$ Dumlupınar Üniversitesi Gediz Meslek Yüksekokulu Tıbbi ve Aromatik Bitkiler, Kütahya, ORCID: 0000-0002-4271-0540
}

(Ilk Geliş Tarihi 7 Mart 2019 ve Kabul Tarihi 7 Temmuz 2019)

(DOI: 10.31590/ejosat.536961)

ATIF/REFERENCE: Karayel H. B. (2019). Kütahya (Çavdarhisar) Yöresinde Yetiştirilen Tıbbi Adaçayı (Salvia officinalis L.) Türünün Çiçeklerindeki Uçucu Yağ Bileşenlerinin Değerlendirilmesi. Avrupa Bilim ve Teknoloji Dergisi, (16), 528-532.

$\ddot{O} z$

Bu çalışma Kütahya (Çavdarhisar) yöresinde yetiştirilen Salvia officinalis L. türünün uçucu yağ bileşenlerini, uçucu yağ oranını ve kalitesini belirlemek amacıyla, 2016-2017 yıllarında yürütülmüştür. Tarla denemeleri tesadüf blokları deneme desenine göre 3 tekerrürlü olarak kurulmuştur. Fideler $50 \mathrm{~cm}$ sıra arası ve $40 \mathrm{~cm}$ sıra üzeri mesafede dikilmiştir. Uçucu yağ analizi salvia officinalis $\mathrm{L}$. türünün çiçeklerinden su distilasyonu ile elde edilmiştir. Uçucu yağın bileşenleri GS_MS (FID) yoluyla belirlenmiştir. Uçucu yağ oranı, çiçekte ikinci yıl yapılan iki hasatta sırasıyla \%1,32 - \%2,33 olarak ölçülmüştür. Tıbbi adaçayının (Salvia officinalis L.) hasat tarihlerine göre uçucu yağ bileşenlerinde değişim olduğu gözlemlenmiştir. Birinci hasat yaz ayında yapılmıştır ve bu biçimde uçucu yağların ana bileşenleri $\alpha$-thujone $\% 26,56,1,8$-Cineole $\% 14,01$, Viridiflorol \%14,67; ikinci biçim ise sonbaharda yapılmış ve ana bileşen olarak, $\alpha$-thujone \%39,51, Camphor \%20,22, 1,8-Cineole \%10,27 bulunmuştur. Eğer elde edilmek istenen madde $\alpha$-thujone $(\% 39,51)$ ise, hasat sonbaharda yapılmalidır.

\section{Evaluation Of Essential Oil Components in the Flowers Of Medicinal Sage (Salvia officinalis L.) Species Grown in Kütahya (Çavdarhisar) Region}

\begin{abstract}
This study was carried out in a farmer's field in 2016-2017 in order to determine the essential oil content and quality of the essential oil components of Salvia officinalis L. grown in Kütahya (Çavdarhisar) region. The field experiments were carried as 3 replicates according to randomized block design. The seedlings were planted by a horizontal distance of $50 \mathrm{~cm}$ and vertical distance of $40 \mathrm{~cm}$. The essential oil analysis was performed on the flowers of Salvia officinalis L. by water distillation. The components of the volatile oil were determined by hydrodistillation method (GC MS/FID). The plants were harvested twice in the second year and the percentages of essential oil acquired from the flowers were $1.32 \%$ and $2.33 \%$ respectively. There has been a change in the volatile oil component rates according to the harvest dates of medicinal sage (Salvia officinalis L.). The first harvest was made in the summer and the main components of the essential oils were $\alpha$-thujone 26,56\%, 1,8-Cineole 14,01\%, Viridiflorol 14,67\% whereas the second harvest was made in autumn and the main components were found as follows; $\alpha$-thujone 39,51\%, Camphor\% 20,22, 1,8-Cineole $10,27 \%$. If the wanted substance is $\alpha$-thujone (39.51\%), the harvest should be done in autumn.
\end{abstract}

* Sorumlu Yazar: Dumlupınar Üniversitesi Gediz Meslek Yüksekokulu Tıbbi Ve Aromatik Bitkiler, Kütahya, Türkiye, ORCID: 0000-0002-42710540, kbasri23@hotmail.com 


\section{Giriş}

Lamiaceae familyasını temsil eden bitkiler, Türkiye de Akdeniz bölgesinde dağlık bölgelerde bulunmaktadır (Baydar ve ark., 2004). Ülkemiz tıbbi bitkiler açısından dünyanın en zengin florasına sahip ülkelerden biri olmasının yanı sıra köklü bir kültüre de sahiptir. Bitkisel ilaçların daha etkili, daha toksik ve daha pahalı olan sentetik ilaçlarla birlikte kullanımlarında tamamlayıcı rol oynamalarına olanak sağlamakta, tek başlarına ise alternatif terapi aracı olarak diğer sistemlerin enfeksiyonlarında iyileştirici amaçlı olarak kullanımlarını gündeme getirmektedir. Bu yönüyle antibakterial aktiviteye sahip bitkilerin bakteri orijinli insan, hayvan ve bitki hastalıklarının kontrolünde etkili olabileceği bildirilmiştir (Başer ve ark., 1993). 10. yüzyılda orta doğuda hekimler adaçayının yeryüzünde meydana gelen ölümlere karşı bir kurtuluş olacağına inanmışlardır. Bir çok hastalığın tedavisinde mesela enfeksiyon hastalıklarında, epilepside, zehirlenmede, bağırsak problemlerine halk arasında adaçayı ile çözüm aranmaktadır. Günümüzdeki tıbbı kullanımına baktığımızda ise çay formunda tıbbi amaçı olarak kullanıldığını görüyoruz (Onlooker, 1995). Salvia, bitki çayı içinde sıkça yer alan bir bitki olup, terlemeyi önleyici olarak, bronşitin tedavisi, ateş, romatizma, sinirsel rahatsılzlklara karşı tavsiyede bulunulurdu (Kamatoua ve ark., 2005). Lamiaceae (Labiatae) familyası Tıbbi ve Aromatik bitki bakımından en zengin familyalardan biri olup, bu familyaya ait bitkilerin çoğu antik çağlardan bu yana halk ilacı olarak çeşitli hastalıkların tedavisinde kullanılmıștır (Bayram, 2001). Biyolojik aktif bileşenlerini belirlemek için birçok sayıda farmakolojik çalışmalar yapılmıştır. İncelenen türler biyolojik aktivite olarak antimikrobial, antioksidant, antiviral, antitümör, antihidrotik aktivite içermekte olduğu tespit edilmiştir (Parekh ve ark., 2005; Digrak ve ark., 1999). Tibbi adaçayı (Salvia officinalis L.), uçucu yağ içeren, tipik bir Akdeniz bitkisidir. Adaçayı 60-100 cm. aralığında boylanır, yarı çalımsı ve saçak köklere sahiptir. Yapraklar beyazımsı griden gümüş rengine kadar değişen renkte ve tüylüdür (Ceylan, 1996). Adaçayı yaprakları \%0,5-2,5 oranında uçucu yağ taşımaktadır. Kodekslerde uçucu yağ oranının en az \%1,5 olması istenmektedir (Ceylan 1996). Uçucu yağında thujon oranı \%30-50, cineol oranı \%15, borneol oranı $\% 10$ olarak belirtilmektedir (Baytop, 1999). Salvia officinalis L.'de etkili madde miktarının, bitkinin gelişme evresinden daha çok, bitkinin kısımlarına bağlı olduğunu belirtmiştir (Zutic ve ark., 2003). Bu araştırma, iç Ege bölgesinde yetiştirdiğimiz Salvia L. türünün uçucu yağ kompozisyonunun karşılaştırılması ve uçucu yağların değerlendirilmesine yönelik bir çalışmadır. Ayrıca bu çalışmayla; Salvia officinalis L. türünün uçucu yağlarını biçim tarihlerine göre karşılaştırmak, bölgeye uygun bitki kısımlarının uçucu yağ oranı ve uçucu yağ bileşenlerin belirlenmesini tespit etmek. Bölge halkı için ürün çeşitliliğini artırmak, ilaç ve gıda sektörüne katk1 sağlamak amaçlanmıştır.

\section{Materyal ve Metot}

\subsection{Bitki Materyali}

$\mathrm{Bu}$ araştırmada materyal olarak kullanılan tohum Ege Üniversitesi Ziraat Fakültesi Tarla Bitkileri Bölümünde temin edilmiştir. Araştırma 2016-2017 yıllarında Kütahya-Çavdarhisar ilçesinde bir üreticinin tarlasında yürütülmüştür. Deneme alanında 180 bitkiye ihtiyaç duyulduğu için sera koşulları ve tarlaya şaşırtıldıktan sonraki başarısızlıklar göz önüne alınarak 216 bitki deneme alanına şaşırtılmıştır. Köklenen fideler Nisan 2016 tarihinden itibaren tarlaya şaşırtılmaya başlanılmıştır. Fideler tarlaya şaşırtıldıktan hemen sonra can suyu verilmiş̧ir. Tarla denemeleri tesadüf blokları deneme desenine göre 3 tekerrürlü olarak yürütülmüş. Denemede dikim aralığ $150 \times 40 \mathrm{~cm}$ olup her parselde 3 sıra yer almıştır. Parsel büyüklüğü 1,75x5,00=8,75 $\mathrm{m}^{2}$ dir. Her siraya 24 bitki her parselde 72 bitki bulunacak şekilde dikim yapılmıştır. Bitkiler ilk iki hafta her gün hortumla sulanmış. Tutmayan bitkilerin yerine yenileri şaşırtılarak her parselde en az 60 bitki olması sağlanmıştır. İkinci haftadan sonra haftada bir sulama yapılmıştır. Gözlemler ve ölçümler her parselde sağlıklı 60 bitki içerisinde etiketlenen 9 adet bitkilerden elde edilen çiçek örneklerinde yapılmıştır. İlk yıl tek, ikinci yıl iki biçim yapılmış ve biçim zamanı olarak uçucu yağ oranının en yüksek olduğu çiçeklenme başlangıcı tercih edilmiştir.

\subsubsection{Uçucu Yă̆ İzolasyonu}

Deneme uçucu yağ analizinin başlangıcında $20 \mathrm{~g}$ kuru çiçek tartılarak $500 \mathrm{ml}$ 'lik balona alınmıştır. Üzerine $200 \mathrm{ml}$ (örnek miktarına göre değişebilir, yaklaşık 10 kat) saf su eklenip çalkalanmıştır. İki saat süreyle hidrodestilasyon işlemine tabi tutularak uçucu yağ elde edilmiştir. Sistem soğuduktan sonra ve dereceli kısma toplanan uçucu yağ sulu fazdan ayrıldıktan sonra miktarı (ml) tespit edilmiştir. Tartımı alınan örnek miktarına (g) göre $100 \mathrm{~g}$ örnekteki uçucu yağ miktarı uçucu yağ oranı (\%) olarak hesaplanmıştır (Tabanca ve ark., 2006).

\subsubsection{Uçucu Yağ Kompozisyonunun GC-MS ile Belirlenmesi}

Bileşen analizleri Batı Akdeniz Tarımsal Araştırma Enstitüsü Araştırma Laboratuvarından yapılmış̧ır. Örnekler 1:100 oranında hekzan ile seyreltilip Gaz kromatografisi (Agilent 7890A) cihazına $1 \mu$ lolarak 40:1 split oranı ile enjekte edilmiştir. Bileşenlerin ayrımı için kapiler kolon (HP InnowaxCapillary; $60.0 \mathrm{~m}$ x $0.25 \mathrm{~mm}$ x $0.25 \mu \mathrm{m}$ ) kullanılmıştır. Kolon, bitiminde bir ayraç (splitter) 
yardımıyla FID ve kütle spektrometresi dedektörüne (Agilent 5975C) akış 1:1 oranında olacak şekilde ikiye ayrılmıştır. Analizde taşıyıcı gaz olarak $0.8 \mathrm{ml} / \mathrm{dk}$ akış hızında helyum kullanılmıștır. Enjektör sıcaklığ $250^{\circ} \mathrm{C}$ 'de tutulmuş, kolon sıcaklık programı $60^{\circ} \mathrm{C}$ 'de 10 dakika, $60^{\circ} \mathrm{C}^{\prime}$ den $220^{\circ} \mathrm{C}^{\prime}$ ye $4^{\circ} \mathrm{C} /$ dakika $\left(40\right.$ dakika) ve $220^{\circ} \mathrm{C}$ 'de 10 dakika - toplamda 60 dakika olacak şekilde ayarlanmıştır. Kütle detektörü için tarama aralı̆̆ $(\mathrm{m} / \mathrm{z}) 35-450$ atomik kütle ünitesi ve elektron bombardımanı iyonizasyon enerjisi 70 eV'dir. Uçucu yağın bileșenlerinin teşhisinde OIL ADAMS, WILEY ve NIST kütüphanelerinin verileri esas alınmıştır. Uçucu yağ bileşen oranlarında ise FID dedektörünün verileri kullanılmıştır. (Özek ve ark., 2010)

\section{Araştırma Sonuçları ve Tartışma}

$\mathrm{Bu}$ araştırmada incelenen Salvia türünün uçucu yağ oranı (\%1,32-2,33 ) ve kompozisyonunun bitkinin biçim sayısına göre değişim göstermiştir.

\subsection{Uçu Yağ İçeriği (\%)}

Uçucu yağ oranı konusunda yapılan çalışmalarda; Rio de Janeiro Eyaleti'nden Petrópolis'teki taze adaçayı yaprağın (Salvia officinalis L.) 'dan elde edilen uçucu yağ oranı \%2,3 bulunmuştur (Porte ve ark., 2013). Bulgaristan'da toplanan Salvia officinalis L. bitkisinin uçucu yağ oranı \%0,93 olarak tespit edilmiştir (Damyanova ve ark., 2016). Uçucu yağ oranı drog çiçekte \%0,50-0,58 arasında bulunmuştur (Yılmaz,1988). Adana ve Pozantı'da yürüttüğü çalışmada S. officinalis L.' in uçucu yağ oranı yaprakta \%1,002,23, çiçekte \%0,73-2,11 arasında bulmuştur (Yenikalaycı,1998). Uçucu yağ oranı ikinci yıl iki biçimde sırasıyla \%1,32-2,33 olarak ölçülmüş farklı yerlerde aynı bitki ile yapılan diğer çalışmalarda elde edilen değerlerle benzer bulunmuştur.

\subsection{Uçucu Yağın Bileşimi (\%)}

Salvia officinalis L. toprak üstü organlarından elde edilen uçucu yağın analizinde çiçekte ikinci yıl birinci biçimde 20, ikinci biçimde 9 bileşen tanımlanmıştır. Bu bileşenler toplam yağın çiçekte birinci biçimde $\% 100$, ikinci biçimde \%100 kısmını oluşturmuştur. Salvia officinalis L. türüne ait çiçeklerde elde edilen uçucu yağ oranı bileşenlerin değerleri birinci biçimde ve ikinci biçimde elde edilen örneklerle belirlenmiştir. Salvia officinalis L. türünün uçucu yağ bileşenlerin değerleri ayrı ayrı olacak şekilde Tablo 3.2.1'de gösterilmiştir. Salvia officinalis L. türünün çiçeklerinde birinci biçim yaz ayında (05.07.2017) yapılmış uçucu yağın ana bileşenleri, $\alpha$-thujone \%26,56, 1,8-Cineole \%14,01, Viridiflorol \%14,67, ikinci biçim sonbaharda (03.10.2017) yapılmış ana bileşen olarak, $\alpha$-thujone \%39,51, Camphor \%20,22, 1,8-Cineole \%10,27 olarak elde edilmiştir. Çiçekte ana bileşen olarak $\alpha$-thujen, 1,8-cineole, viridiflorol, Camphor olarak bulunmuştur. Salvia officinalis L. türünün bitki kısımlarına göre uçucu yağ bileşenleri belli ölçüde değişiklik göstermektedir. Salvia officinalis L. türünde ana bileşeni çiçekte $\alpha$-thujen olarak gerçekleşmiştir.

Tablo 3.2.1. Salvia officinalis L. türünün uçucu yağının (çiçek) biçim sayısına göre bileşen miktarının (\%) değişimi

\begin{tabular}{llcc}
\hline & & \multicolumn{2}{c}{ Çiçek } \\
\hline S.no & Bileşen adi & 1. Biçim & 2. Biçim \\
\hline 1 & Cis-Salvene & $0,77 \pm 0,042426$ & - \\
2 & $\alpha$-Pinene & $3,90 \pm 0,042426$ & - \\
3 & Camphene & $1,25 \pm 0,021213$ & $5,26 \pm 0,494975$ \\
4 & $\beta$-Pinene & $3,89 \pm 0,06364$ & - \\
5 & $\beta$-Myrcene & $0,72 \pm 0,049497$ & - \\
6 & dl-Limonene & $0,91 \pm 0,021213$ & - \\
7 & 1,8 -Cineole & $14,01 \pm 0,219203$ & $10,27 \pm 0,487904$ \\
8 & $\alpha$-Thujone & $26,56 \pm 0,070711$ & $39,51 \pm 0,247487$ \\
9 & $\beta$-Thujone & $5,25 \pm 0,219203$ & $4,60 \pm 0,183848$ \\
10 & Camphor & $3,62 \pm 0,113137$ & $20,22 \pm 0,523259$ \\
12 & Bornyl acetate & $0,65 \pm 0,219203$ & $5,62 \pm 0,254558$ \\
13 & $\beta$-Caryophyllene & $5,63 \pm 0,035355$ & $3,79 \pm 0,13435$ \\
14 & $\alpha$-Humulene & $5,60 \pm 0,183848$ & \\
15 & Borneol & $1,95 \pm 0,021213$ & $3,87 \pm 0,077782$ \\
16 & Caryophyllene oxide & $0,59 \pm 0,275772$ & - \\
17 & Humulene epoxide II & $1,14 \pm 0,296985$ & - \\
18 & Viridiflorol & $14,67 \pm 0,155563$ & $6,96 \pm 0,042426$ \\
19 & Carvacrol & $1,05 \pm 0,424264$ & - \\
20 & Manool & $7,84 \pm 0,084853$ & - \\
\hline & Toplam & $\% 100$ & $\% 100$ \\
\hline & & &
\end{tabular}


Ayrıca araştırma sonuçlarına göre uçucu yağ bileşenleri üzerine yetişme ortamı, biçim sayısı gibi faktörlerin etkili olduğunu belirtmiş (Yenikalayc1, 1998). Çalışmamız benzer şekilde; Adana ve Pozantı'da yürüttüğü çalışmada S. officinalis L.' in Uçucu yağ bileşenleri çiçekte, thujon \%12,61, $\alpha$ - pinen \%3,76, sabinen \%12,1, $\beta$ - pinen \%20,4, 1,8-cineole \%23,8, Camphor \%7,5, borneol $\% 12,3$, bornil asetat $\% 3,2$, caryophyllene $\% 5,7$ olarak tespit etmiştir (Ekren, S ve ark. 2007). Bu araştırmada, uçucu yağın ana bileşenleri, thujone $\% 26,68$, (E) - $\beta$-karyofilen $\% 7,47,1,8$-cineol $\% 7,19, \alpha$-humulen $\% 6,11, \beta$-Pinen $\% 5,44, \beta$-thujone $\% 5,35$, Camphor \%4,84, allo-aromadendrene \%4,55, borneol \% 3,69 ve $\alpha$-pinen \% 3,58 (Damyanova ve ark., 2016). Yapılan çalışmada, 5 farklı lokaliteden topladığı Salvia officinalis L. yapraklarında uçucu yağ oranının \%1,4-3,5 arasında değiştiğini, 19 adet uçucu yağ bileşeni bulunduğunu, en yüksek miktarda thujone olduğunu bildirmişlerdir (Kustrak ve ark., 1984). Salvia officinalis'de uçucu yağ verimi ve bileşenlerinin mevsimsel değişimlerini inceledikleri çalışmalarında, tıbbi adaçayının yapraklarını Haziran-Aralık ayları arasında $7 \mathrm{kez}$ aynı yerden toplamışlardır. Uçucu yağın verim ve bileşenlerinde aydan aya değişmeler olduğunu, en fazla uçucu yağ oranının temmuz ayında toplanan yapraklardan elde edildiğini, thujonun en yüksek ekim ayında olduğunu belirtmişlerdir (Pitarevic ve ark., 1984). Sırbistan ve Karadağ'dan topladıkları Salvia officinalis L. popülasyonlarda yapraklarda ki uçucu yağ miktarını çiçeklerden daha fazla bulduklarını, Sırbistan popülasyonlarının ortalama uçucu yağ oranının \%1,66, Karadağ popülasyonlarında ise yapraklarda \%1,41, çiçeklerde \%1,13 olduğunu belirtmiş̧lerdir. Çiçeklerde uçucu yağ ana bileşenleri, $\alpha$-thujone \%9,97, camphor $\% 5,82$, borneol \%6,35, manool \%13,48 olarak tespit etmişlerdir (Couladis ve ark., 2002). Tıbbi adaçayında hasat zamanı ve biçim yüksekliği ile ilgili yaptıkları araştırmada, bitkinin değişik kısımlarından elde ettikleri uçucu yağ oranları çiçeklerde $\% 0,6$ olarak bulunmuştur. Tespit edilen 25 uçucu yağ bileşenlerinden, en fazla miktarda bulunanlar: $\alpha$ ve $\beta$-thujone, 1,8 -cineole ve viridiflorol olarak tespit edilmiştir (Zutic ve ark., 2003). Çiçekte ikinci biçimde elde edilen Uçucu yağın ana bileşeni $\alpha$-thujone \%39,51 olarak bulunmuştur. İkinci biçimde elde edilen $\alpha$-thujone oranı yapılan diğer çalışmalarla karşılaştırıldığında daha yüksek bulunmuştur.

\section{Sonuç}

Salvia L. türünün uçucu yağ kompozisyonunun biçim zamanındaki ekolojik faktörlere bağlı olarak uçucu yağların değerlendirmesine yönelik bir çalışmadır. Çavdarhisar ilçesinde yaz ayında yapılan biçimde 20 bileşen, sonbaharda yapılan biçimde 9 bileşen tanımlanmıştır. Uçucu yağ oranı en yüksek çiçekte ikinci biçimde $\% 2,33$ olarak tespit edilmiştir. Çiçekte elde edilen ana bileşen birinci biçimde $\alpha$-thujone \%26,56, ikinci biçimde elde edilen ana bileşen $\alpha$-thujone \%39,51 olarak elde edilmiş̧ir. Ekolojik faktörlere göre uçucu yağ bileşenlerinin de farklılık gösterdiği düşünüldüğünde farklı lokasyonlarından farklı Salvia türleri üzerinde daha fazla çalışmaların yürütülmesi faydalı olacaktır.

\section{Kaynakça}

Başer, K.H.C., Özek, T., Akgül, A.,Tumen, G. 1993. "Composition of the Essential Oil of Nepeta Racemosa Lam.," J.Essent.Oil.Res., 5(2): 215-217.

Baydar, H., Sagdic,O.,Ozkan,G, Karadogan T. 2004. "Antibacterial Activity and Composition of Essential Oils from Origanum, Thymbra and Satureja Species with Commercial Importance in Turkey", Food Control, 15: 169-172.

Bayram, E. 2001."Batı Anadolu Florasında Yetişen Anadolu Adaçayı (Salvia fructicosa Mill)'Nda Uygun Tiplerin Seleksiyonu Üzerine Araştırma", Türk. J. Agric. For: 351-357.

Baytop, T. 1999. Türkiye'de Bitkiler İle Tedavi Geçmişte ve Bugün (II. Basım).Nobel Tıp Kitapevleri.

Ceylan, A. 1996, Tıbbi Bitkiler-II (Uçucu Yağ Bitkileri) E.Ü.Z.F. Yayınları No:481, Bornova, İzmir, ISBN:975-483-362-1, S.225-240.

Couladis, M., Tzakou, O., Mimica-Dukic, N., Jancic, R. and Stojanovic, D. 2002. Essential oil of Salvia officinalis L. from Serbia and Montenegro. Flavour and Fragrance Journal. 17 (2): 119-126.

Damyanova, S., Mollova, S., Stoyanova, A., Gubenia, O. 2016. Chemical composition of Salvia officinalis L. essential oil from Bulgaria. Ukrainian Food Journal, 5(4).

Digrak, M., İlçim, A., Alma, M. H. 1999."Antimicrobial Activites of the Extracts of Various Plants (Valex, Mimosa Bark,Gallnut Powders, Salvia Sp. And Phlomis Sp.)",Tr. J. Of Biology,, 23: 241-248.

Ekren.S.,Ark. Farklı Biçim Yüksekliklerinin Adaçayı (Salvia officinalis L.) Genotiplerinde Agronomik ve Teknolojik Özelliklere Etkisinin Belirlenmesi. Ege Üniv. Ziraat Fak. Derg., 2007, 44 (1): 55-70 .izmir.

Ekren, S., Sönmez, Ç., Sancaktaroğlu, S., Bayram, E. 2007. Farklı biçim yüksekliklerinin adaçayı (Salvia officinalis L.) genotiplerinde agronomik ve teknolojik özelliklere etkisinin belirlenmesi. Ege Üniversitesi Ziraat Fakültesi Dergisi, 44(1), 55-70.

Kamatoua, G.P.P., Viljoen A.M., Gono-Bwalya A.B., van Zyl R.F., van Vuuren R.L.,Lourens, A.C.U., Baser, K.H.C., Demirci B., Lindsey K.L., van Staden J.,Steenkamp P. 2005."The in Vitro Pharmacological Activities and a Chemical Investigation of Three South African Salvia Species",Journal of Ethnopharmacology, 102 (3): 382-390.

Kustrak, D., Kuftinec, J. and Blazevic, N. 1984. Yields and composition of sage oils from different regions of the Yugoslavian Adriatic coast. Journal of Natural Product, 47(3): 520-524. CAB Abstracts .

Parekh, J., Jadeja,D., Chanda, S. 2005."Efficacy of Aqueous and Methanol Extracts of Some Medicinal Plants for Potential Antibacterial Activity",Turk J.Bio., 29: 203-210.

Pitarevic, I., Kuftinec, J., Blazevic, N. and Kustrak, D. 1984. Seasonal variation of essential oil yield and composition of Dalmatian sage, Salvia officinalis L. Journal of Natural Product, 47(3): 409-412. CAB Abstracts.

Porte, A., R. L. O. Godoy, and L. H. Maia-Porte. 2013. "Chemical composition of sage (Salvia officinalis L.) essential oil from the Rio de Janeiro State (Brazil)." Revista Brasileira de Plantas Medicinais 15.3: 438-441.

Onlooker, "Sage against Age", The Pharmaceutical Journal Vol, 255:708 (1995).

Yenikalaycı, A. 1998. Çukurova Bölgesinde Doğal Adaçayı Türleri (Salvia ssp.) ile Tıbbi Adaçayı (Salvia officinalis L.)'nın Kültürü ve Kemotaksonomik Arastırmalar. Doktora Tezi, Çukurova Üniversitesi Fen Bilimleri Enstitüsü, Tarla Bitkileri Anabilim Dalı, Adana. 


\section{Avrupa Bilim ve Teknoloji Dergisi}

Yılmaz, H. 1988. Tıbbi adaçayı (Salvia officinalis L.)'nda ekolojik ve morfogenetik varyabilite. (Yüksek Lisans Tezi), Çukurova Üniversitesi Fen Bilimleri Enstitüsü Tarla Bitkileri Anabilim Dalı.

Zutic, I., E. Putievsky, N. Dudai. 2003. Influence of Harvest Dynamics and Cut Height on Yield Components of Sage Salvia officinalis L., Journal of Herbs, Spices and Medicinal Plants, Vol.10, No:4. 